\title{
Metabolism of Branched-Chain Amino Acids in Fibroblasts from Patients with Maple Syrup Urine Disease and Other Abnormalities of Branched-Chain Ketoacid Dehydrogenase Activity
}

\author{
I. YOSHIDA, L. SWEETMAN, AND W. L. NYHAN \\ Department of Pediatrics, University of California San Diego, La Jolla, California 92093 and the Department of \\ Pediatrics and Child Health, Kurume University, Kurume, Japan
}

\begin{abstract}
The metabolism of branched-chain amino acids was studied in cultured fibroblasts from patients with branched-chain ketoacid dehydrogenase deficiency using $1-{ }^{14} \mathrm{C}$ - and $\mathrm{UL}-{ }^{14} \mathrm{C}$-leucine and valine. The formation of ${ }^{14} \mathrm{CO}_{2}$ from $1{ }^{-14} \mathrm{C}$-valine or $1{ }^{14} \mathrm{C}$-leucine was $1-3 \%$ of normal. In fibroblasts of patients with associated lactic acidemia the values were $4-29 \%$ of control. Analysis of organic acid products revealed that in both patients and controls the amount of labeled $\alpha$-ketoisovalerate recovered after incubation with $1-{ }^{14} \mathrm{C}$-valine was one-third of the amount of $\alpha$-ketoisocaproate recovered after incubation with $1-{ }^{14} \mathrm{C}$-leucine. Very little $\alpha$-hydroxyisocaproate was produced, while the amount of $\alpha$-hydroxyisovalerate was about $10 \%$ of the $\alpha$-ketoisovalerate. Unexpectedly $\beta$-hydroxyisobutyrate ws found to be the major metabolic product of $\mathrm{UL}-{ }^{14} \mathrm{C}$-valine in normal fibroblasts. Large accumulations of $\beta$-hydroxyisovalerate were found in normal fibroblasts using $\mathrm{UL}_{-}{ }^{14} \mathrm{C}$-leucine. There were little or no conversions to these compounds in fibroblasts of patients with branched-chain ketoacid dehydrogenase deficiency. There were substantial conversions in the patients in whom dehydrogenase deficiency was associated with lactic acidemia. (Pediatr Res 20: 169-174, 1986)
\end{abstract}

\section{Abbreviations}

BCKADH, branched-chain ketoacid dehydrogenase MSUD, maple syrup urine disease $\mathbf{E}_{3}$, dihydrolipoyl dehydrogenase LPC, liquid partition chromatography

MSUD results from defective activity of the BCKADH complex (1). The concentrations of leucine in the blood of patients with MSUD are generally higher than those of valine and isoleucine, indicating that there are differences in metabolism among the three ketoacids. Several variant forms of BCKADH deficiency have been described (2-4). Patients have also been described in whom deficiency of BCKADH was secondary to a deficiency of $E_{3}(5,6)$. We have also studied a patient in whom

Received February 12, 1985; accepted September 26, 1985.

Address reprint requests and correspondence to Dr. Lawrence Sweetman, Department of Pediatrics, M-009. University of California San Dicgo, La Jolla, CA 92093

Supported by U.S. Public Health Service Grant HD04608 from the National Institute of Child Health and Human Development. and General Clinical Research Center Grant RR-00827 from the Division of Research Resources. National Institutes of Health. Bethesda, MD, and NF 1-377, from the March of Dimes Birth Defects Foundation, White Plains, NY. there was deficiency of the activities of BCKADH, pyruvate dehydrogenase and $\alpha$-ketoglutarate dehydrogenase in whom the activity of $\mathrm{E}_{3}$ was normal (Yoshida I, Sweetman L, Nyhan WL, Robinson $\mathrm{BH}$, unpublished data).

We have studied the metabolic pathways of the branchedchain amino acids to $\mathrm{CO}_{2}$ and to organic acid reaction products in fibroblasts of patients with different types of defects in the activity of BCKADH.

\section{MATERIALS AND METHODS}

Materials. Thiamine $\cdot \mathrm{HCl}$, bovine serum albumin, and glucose were obtained from Sigma Company, St. Louis, MO. $1-^{14} \mathrm{C}-1-$ leucine $(53.7 \mathrm{mCi} / \mathrm{mmol})$ and $1-{ }^{14} \mathrm{C}$-L-valine $(47.9 \mathrm{mCi} / \mathrm{mmol})$ were obtained from New England Nuclear, Boston, MA. UL${ }^{14} \mathrm{C}$-L-leucine $(300 \mathrm{mCi} / \mathrm{mmol})$ and UL- ${ }^{14} \mathrm{C}$-L-valine $(250 \mathrm{mCi} /$ mmol) were obtained from ICN Pharmaceuticals, Inc., Irvine, CA. Unlabeled L-amino acids were obtained from Calbiochem, La Jolla, CA. $\beta$-Phase liquid scintillation fluid was purchased from Westchem Products, San Diego, CA; and Cab-O-Sil thixotropic gel powder from Packard, Downers Grove, IL. Silicic acid (100 mesh suitable for chromatography) was purchased frorn Mallinkrodt, Paris, KY, dried overnight at $130^{\circ} \mathrm{C}$ and silicic acid was prepared for column chromatography by mixing $92 \mathrm{~g}$ with $50 \mathrm{ml} 0.05 \mathrm{~mol} /$ liter sulfuric acid. Other chemicals were reagent grade.

Cell lines and conditions of culture. Human fibroblasts were cultured from skin biopsies of normal subjects (FS1, 2, 3, and 5) and patients with defects in BCKADH. Fibroblasts of a patien.t with classical MSUD (GM 612) were obtained from the Human Genetic Mutant Cell Repository, Camden, NJ. Three patients had the clinical phenotype of the intermittent form of BCKADH $(\mathrm{CH}, \mathrm{SR}$, and KF) $(1,2)$. One patient (TK) (5) had a deficiency of $E_{3}$. EB (Yoshida I, Sweetman L, Nyhan WL, Robinson BH, unpublished data) had branched-chain ketoaciduria, lactic acidemia, and $\alpha$-ketoglutaric aciduria, but the activity of $\mathrm{E}_{3}$ was normal. Fibroblasts were cultured in roller bottles in Eagle"s minimal essential medium with $10 \%$ fetal calf serum and penicillin and streptomycin. The cells were harvested using trypsinEDTA, suspended in minimal essential medium-10\% fetal calf serum, counted, washed three times with isotonic Krebs-Ringer phosphate buffer (7) by centrifugation, and resuspended at a concentration of $2 \times 10^{6}$ cells in $280 \mu \mathrm{l}$ of buffer containing 5.55 $\mathrm{mmol} /$ liter glucose and $1 \mathrm{mg} / \mathrm{ml}$ of bovine serum albumin. Krebs-Ringer phosphate buffer $\mathrm{pH} 7.4$ was used for studies of 1${ }^{14} \mathrm{C}$-amino acids and Krebs-Ringer bicarbonate buffer $\mathrm{pH} 7.4$ was used for studies of UL- ${ }^{14} \mathrm{C}$-amino acids. The addition of 1 $\mathrm{mg} / \mathrm{ml}$ of bovine serum albumin to the incubations increased the number of intact cells remaining after $90 \mathrm{~min}$ of incubation. 
The addition of $5.55 \mathrm{mmol} /$ liter of glucose increased the ${ }^{14} \mathrm{CO}_{2}$ production from $1-{ }^{14} \mathrm{C}$-leucine in normal cells by more than 2 fold.

Studies of the metabolism of $1-{ }^{14} \mathrm{C}$-leucine and $1-{ }^{14} \mathrm{C}$-valine. Assays for the oxidation of $1-^{14} \mathrm{C}$-labeled branched-chain amino acids to ${ }^{14} \mathrm{CO}_{2}$ were modified from Dancis et al. (4). Incubations were done in a total volume of $300 \mu \mathrm{l}$ in vials containing plastic cups suspended through rubber caps for the trapping of $\mathrm{CO}_{2}$. The standard incubation contained $2 \times 10^{6}$ cells, $280 \mu \mathrm{l}$ of KrebsRinger phosphate buffer with $5.55 \mathrm{mmol} /$ liter glucose, $1 \mathrm{mg} / \mathrm{ml}$ bovine serum albumin, $5 \mu \mathrm{l}$ of thiamine $\cdot \mathrm{HCl}$ (final concentra- tion $5 \mathrm{mmol} / \mathrm{liter}$ ), and $15 \mu \mathrm{l}$ of $1-{ }^{14} \mathrm{C}$-leucine or $1-{ }^{14} \mathrm{C}$-valine with a specific activity of $0.4 \mathrm{mCi} / \mathrm{mmol}$ to give a final concentration of $1 \mathrm{mmol} /$ liter. The blanks were incubated without cells. After incubation for $90 \mathrm{~min}$ at $35^{\circ} \mathrm{C}$ in a shaking water bath, the incubation vials were placed on ice. To acidify the incubations and evolve ${ }^{14} \mathrm{CO}_{2}, 25 \mu \mathrm{l}$ of $6 \mathrm{~mol} /$ liter sulfuric acid were injected into the incubation mixture and $400 \mu \mathrm{l}$ of $3 \mathrm{~mol} / \mathrm{liter}$ $\mathrm{KOH}$ were injected into the suspended cup. After trapping ${ }^{14} \mathrm{CO}_{2}$ for $1 \mathrm{~h}$ while the vials were on ice, the $\mathrm{KOH}$ was transferred to scintillation vials and each cup rinsed two times with $500 \mu \mathrm{l}$ of $\mathrm{H}_{2} \mathrm{O}$. Bray's liquid scintillation fluid with $3 \%$ Cab-O-Sil $(15 \mathrm{ml})$
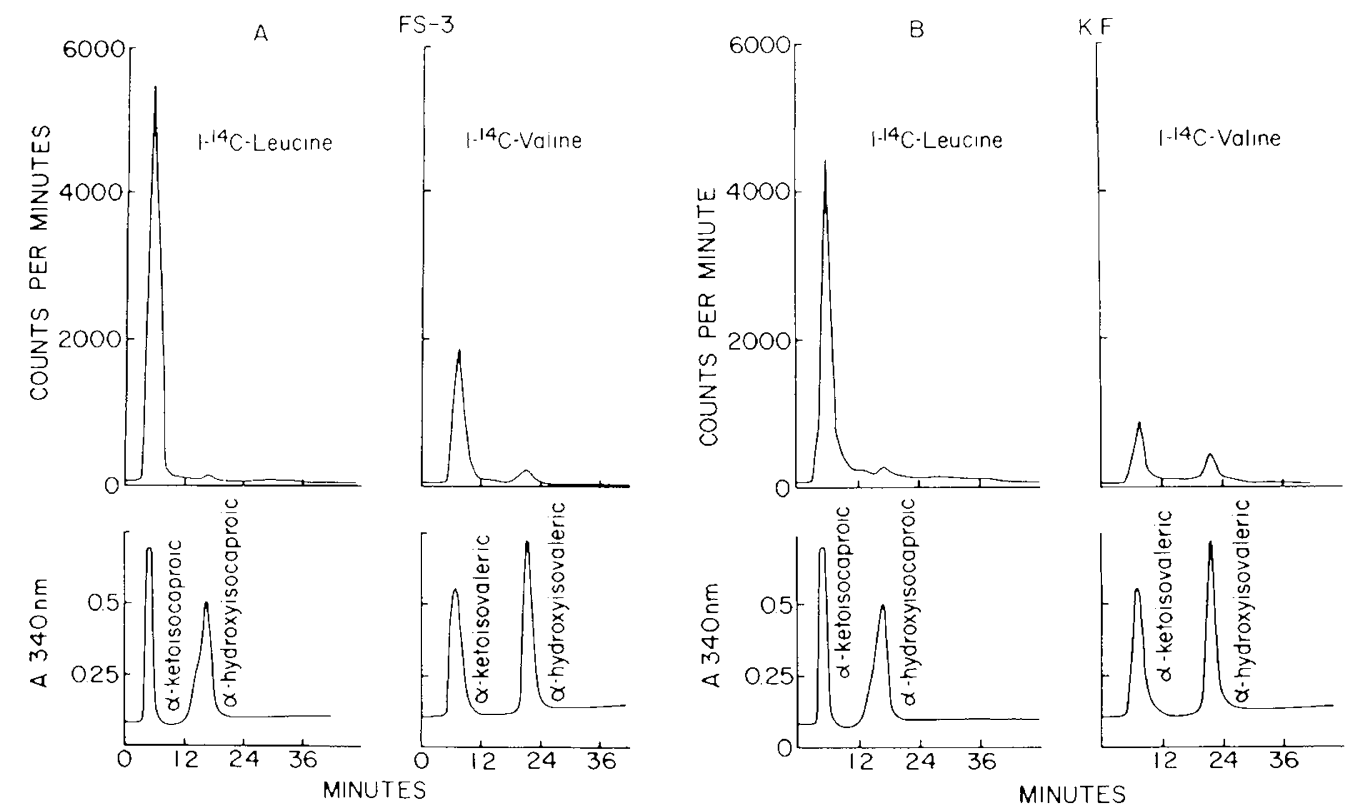

Fig. 1. Transamination of $1-{ }^{14} \mathrm{C}$-leucine and $1-{ }^{14} \mathrm{C}$-valine by fibroblasts derived from a normal individual (FS-3) and a patient with an intermittent branched-chain ketoaciduria phenotype (KF). The radioactive products shown above represent the conversion of substrates to products, while the absorption at $340 \mathrm{~nm}$ shown below represents the position of added standards. Incubations were carried out for 90 min with $2 \times 10^{6}$ cells in 1 $\mathrm{mmol} / \mathrm{liter}(0.4 \mathrm{mCi} / \mathrm{mmol})$ of $1-{ }^{14} \mathrm{C}$-leucine or $1-{ }^{14} \mathrm{C}$-valine. Liquid partition chromatography was carried out using $1 \% 2$-methyl-2-butanol alcohol of the free acids as described in "Materials and Methods."
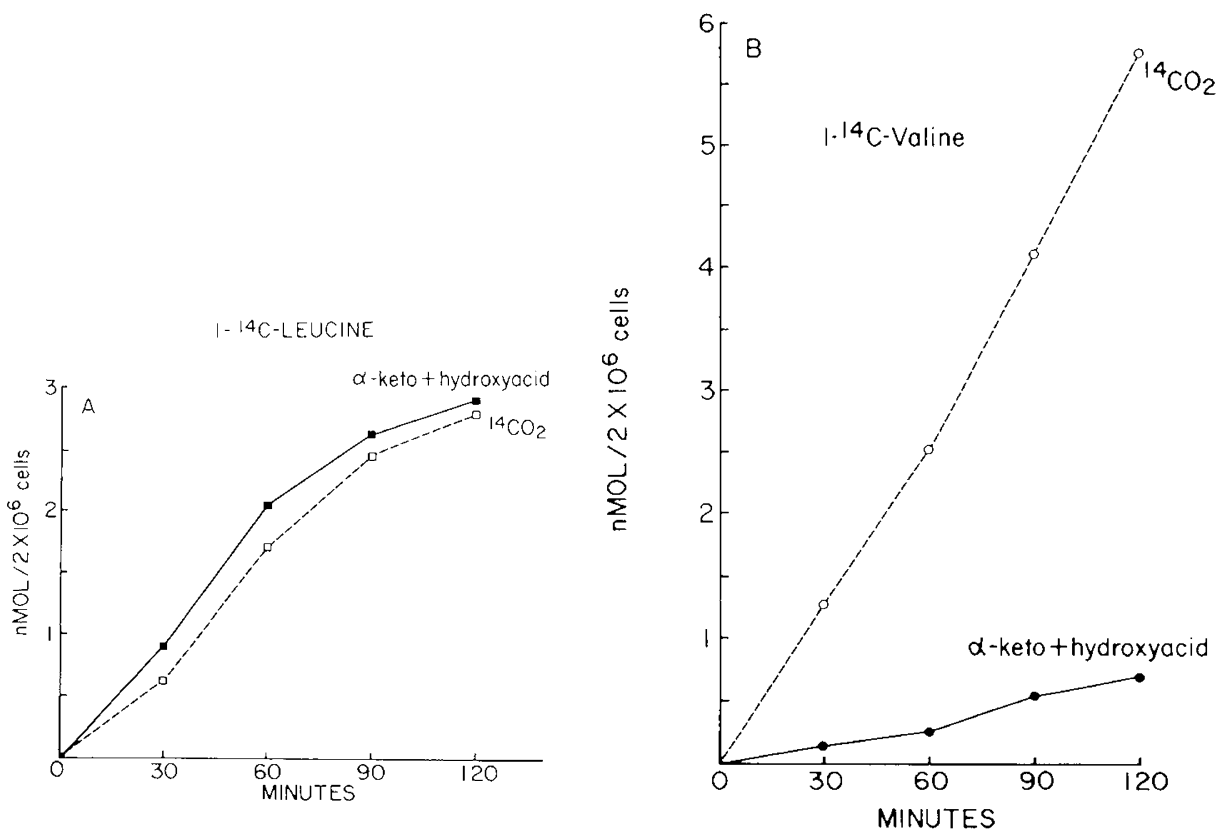

Fig. 2. Time course of the metabolism of $1-{ }^{14} \mathrm{C}$-leucine $(l e f t)$ and $1-{ }^{14} \mathrm{C}$-valine (right) with control fibroblasts. The curves represent conversions to ${ }^{14} \mathrm{CO}_{2}$ and to the sum of $\alpha$-keto and $\alpha$-hydroxy acids; $2 \times 10^{6}$ fibroblasts were incubated in $1 \mathrm{mmol} / \mathrm{liter}(0.4 \mathrm{mCi} / \mathrm{mmol})$ of $1-{ }^{14} \mathrm{C}$-leucine or 1 ${ }^{14} \mathrm{C}$-valine. 

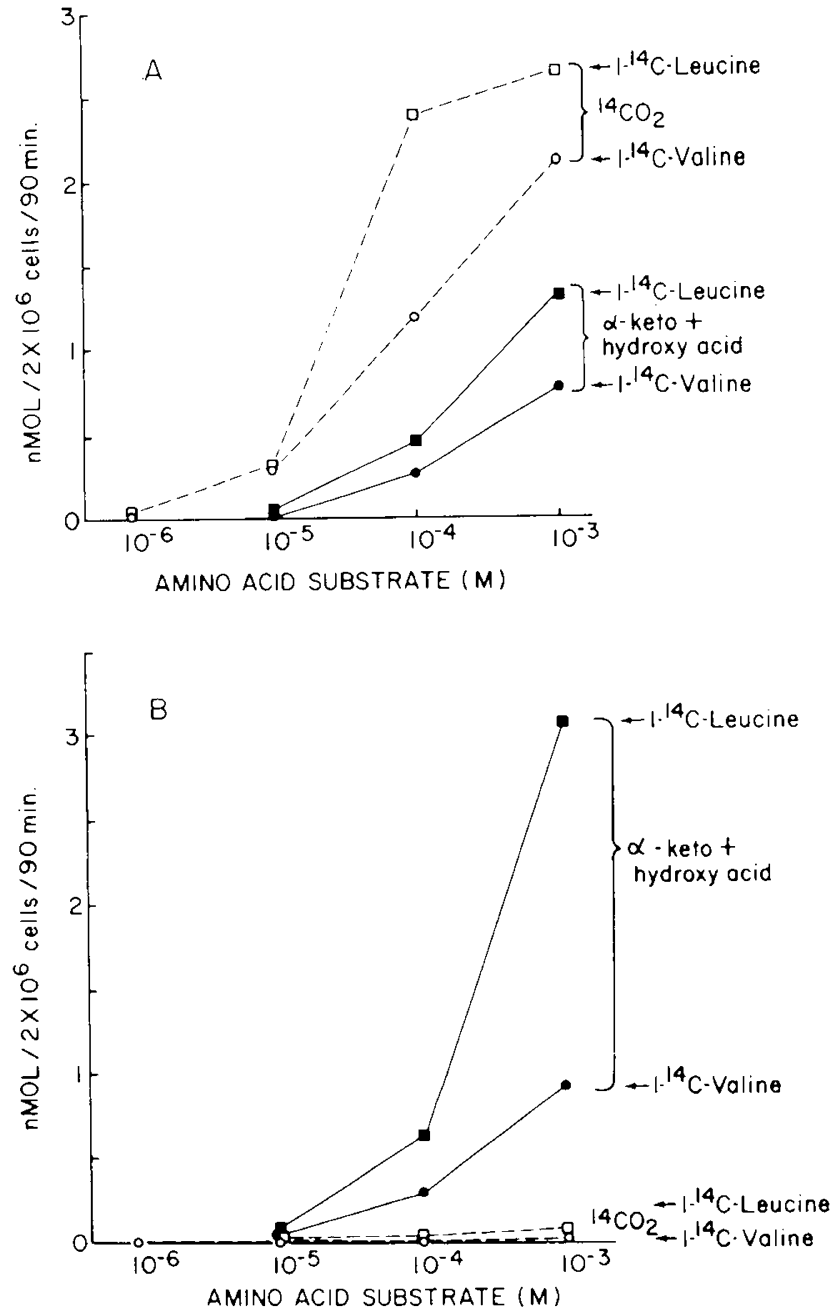

Fig. 3. Conversion of $1-{ }^{14} \mathrm{C}$-leucine and $1-{ }^{14} \mathrm{C}$-valine to ${ }^{14} \mathrm{CO}_{2}$ and to the respective $\alpha$-keto and $\alpha$-hydroxy acid products with varying concentrations of substrate. Incubations with $2 \times 10^{6}$ cells were carried out for $90 \mathrm{~min}$ in control fibroblasts $(A)$ and in those of the patient with classic MSUD $(\operatorname{GM} 612)(B)$. For all concentrations of amino acids the specific activity was $0.4 \mathrm{mCi} / \mathrm{mmol}$.

(8) was added, and the vials counted in a Beckman LS250 Scintillation Spectrophotometer with external standardization for quenching. The acidified assay mixtures were stored at $-20^{\circ} \mathrm{C}$ until analyzed for $\alpha$-keto and $\alpha$-hydroxy acids by LPC modified from Sweetman (9). The acidified samples to which were added 1 micromole of each of the appropriate unlabeled $\alpha$-keto and $\alpha$ hydroxy acids were adsorbed onto dried silicic acid and placed on a $0.6 \mathrm{~cm} \mathrm{ID} \times 45 \mathrm{~cm}$ column of hydrated silicic acid and eluted with $1 \%(\mathrm{v} / \mathrm{v})$ 2-methyl-2-butanol in chloroform at 2.5 $\mathrm{ml} / \mathrm{min}$. The effluent was titrated spectrophotometrically by mixing with $0.5 \mathrm{ml} / \mathrm{min}$ of $5 \mathrm{mmol} /$ liter $\mathrm{Na} O$-nitrophenolate in $95 \%$ ethanol, and twenty 2 min fractions were collected. The fractions were dried overnight under a heat lamp in a hood. The dried fractions were dissolved in $0.5 \mathrm{ml}$ of $35 \mathrm{mmol} /$ liter acetic acid to decolorize the indicator and counted in $5 \mathrm{ml}$ of $\beta$-phase liquid scintillation fluid.

Studies of the metabolism of $U L-{ }^{14} C$-leucine and $U L-{ }^{14} C$ valine. Incubations with fibroblasts were identical to those using the $1-{ }^{14} \mathrm{C}$-amino acids except that the buffer was Krebs-Ringer bicarbonate, and the specific activity of the amino acids was 10fold higher $(4 \mathrm{mCi} / \mathrm{mmol})$. After incubation for $90 \mathrm{~min}$ at $35^{\circ} \mathrm{C}$, the reactions were stopped by placing on ice, and unlabeled standard organic acids were added. The standards for UL ${ }^{14} \mathrm{C}_{-}$ leucine were $1 \mu \mathrm{Eq}$ of $\alpha$-ketoisocaproic acid and $0.5 \mu \mathrm{Eq}$ each of $\beta$-methylcrotonic, 3-hydroxyisovaleric, $\beta$-hydroxy- $\beta$-methylglutaric, and citric acids in $87.5 \mu \mathrm{l}$. The standards for UL- ${ }^{14} \mathrm{C}$-valine were $1 \mu \mathrm{Eq}$ of $\alpha$-ketoisovaleric acid and $0.5 \mu \mathrm{Eq}$ each of $\beta$ hydroxyisobutyric, propionic, and citric acids in $62.5 \mu$ l. The incubation mixtures with standards were adjusted to $\mathrm{pH} 12$ or greater with $50 \mu \mathrm{l}$ of $10 \mathrm{~mol} / 1 \mathrm{NaOH}$ and left at room temperature for 15 min to hydrolyze coenzyme A esters. Oximes of the $\alpha$-ketoacids were formed by adding $10 \mu \mathrm{l}$ of a fresh solution of $3.6 \mathrm{~mol} /$ liter of hydroxylamine. $\mathrm{HCl}$ and leaving at room temperature for $15 \mathrm{~min}$. The ${ }^{14} \mathrm{C}$-organic acids were separated by acidification with $50 \mu \mathrm{l} 6 \mathrm{~mol} / \mathrm{liter}$ sulfuric acid and LPC on silicic acid as described for the $\alpha$-keto and $\alpha$-hydroxy acids except that a concave upward gradient of 2-methyl-2-butanol in chloroform was used, and 110 fractions were collected, dried, and counted. The total dmp in the radioactive peaks were calculated, and the dmp of the peaks from the blanks without cells were subtracted.

\section{RESULTS}

The LPC separation of the $1-{ }^{14} \mathrm{C}$-branched-chain $\alpha$-keto and $\alpha$-hydroxy acid products of transamination are shown in Figure 1. The amounts of $1-{ }^{14} \mathrm{C}$-hydroxy acids were a small fraction of the amounts of $1-{ }^{14} \mathrm{C}$-keto acids. Considerably more isotope was recovered in the ketoacid analog of leucine than that of valine in control fibroblasts. There was virtually no isotope of leucine in $\alpha$-hydroxyisocaproic acid but the quantity of isotope of valine in $\alpha$-hydroxyisovaleric acid was about $10 \%$ of that in $\alpha$-ketoisovaleric acid. The conversion of leucine to $\alpha$-ketoisocaproic acid in the patient was about $75 \%$ of that of the control, while the isotope in $\alpha$-ketoisovaleric acid was about one-third in the patient of that of the control incubated with valine, but the isotope in $\alpha$-hydroxyisovaleric acid in the patient was greater than that of the control. These differences did not appear to be significant.

The oxidation of $1-{ }^{14} \mathrm{C}$-leucine and $1-{ }^{14} \mathrm{C}$-valine to ${ }^{14} \mathrm{CO}_{2}$ was linear with time for at least $90 \mathrm{~min}$ and also linear with the quantity of cells (Fig. 2). The extent of oxidation was similar for the two amino acids. The formation of ${ }^{14} \mathrm{C}$ - $\alpha$-keto and $\alpha$-hydroxy acids was also essentially linear for at least 90 min. The sum of the ${ }^{14} \mathrm{C}-\alpha$-keto plus $\alpha$-hydroxy acid analogs from $1-{ }^{14} \mathrm{C}$-valine was considerably less than that from $1-{ }^{14} \mathrm{C}$-leucine. The total amounts of isotope in these organic acids was virtually identical to that in $\mathrm{CO}_{2}$ following incubation with leucine, while the amounts in the organic acid products were considerably smaller than that in $\mathrm{CO}_{2}$ following incubation with valine.

Figure $3 \mathrm{~A}$ illustrates the effects of increasing concentrations of ${ }_{1-}^{1-} \mathrm{C}$-leucine and $1-{ }^{14} \mathrm{C}$-valine on the production of ${ }^{14} \mathrm{CO}_{2}$ and ${ }^{14} \mathrm{C}$ - $\alpha$-keto plus $\alpha$-hydroxy acids in normal fibroblasts. The smaller amount of isotope in these organic acid products of valine than those of leucine was observed at each of the higher concentrations studied. The conversion of leucine to $\mathrm{CO}_{2}$ was also greater than that of valine in this study, but this did not appear to be constant (Figs. 2 and 3, Table 1). The concentration curves of $1-{ }^{14} \mathrm{C}$-leucine and $1-{ }^{14} \mathrm{C}$-valine on ${ }^{14} \mathrm{C}$ - $\alpha$-keto and $\alpha$ hydroxy acids in the fibroblasts of the patient with classical MSUD (Fig. 3B) were not different from those of the control. However, oxidation of the amino acids to ${ }^{14} \mathrm{CO}_{2}$ was virtually zero in the patient's cells at each concentration studied.

The data on the oxidation of $1-{ }^{14} \mathrm{C}$-leucine and $1-{ }^{14} \mathrm{C}$-valine to ${ }^{14} \mathrm{CO}_{2}$ were similar for the two amino acids in normal control fibroblasts (Table 1). The means were 2.73 and $3.66 \mathrm{nmol} / 2 \times$ $10^{6}$ cells per $90 \mathrm{~min}$ for leucine and valine, respectively. The oxidation of the amino acids to ${ }^{14} \mathrm{CO}_{2}$ was markedly deficient in the fibroblasts of patients with classical or intermittent MSUD, ranging from 2.5 to $3.2 \%$ of normal for $1-{ }^{14} \mathrm{C}$-leucine and 1.0 to $2.6 \%$ of normal for $1-{ }^{14} \mathrm{C}$-valine. The cells of the patient with deficiency of $\mathrm{E}_{3}$ were considerably more effective in the oxidation of the amino acids than the patients with MSUD. The formation of ${ }^{14} \mathrm{CO}_{2}$ was 25 to $30 \%$ of normal. The patient $\mathrm{EB}$ with 
Table 1. Oxidation of $1-{ }^{14} \mathrm{C}$-leucine and $1-{ }^{14} \mathrm{C}$-valine to ${ }^{14} \mathrm{CO}_{2}$ in

\begin{tabular}{lll}
\multicolumn{3}{c}{ cultured fibroblasts ${ }^{*} \dagger$} \\
\hline Controls & $1-{ }^{14} \mathrm{C}$-leucine & $1-{ }^{14} \mathrm{C}$-valine \\
FS 1 & & \\
FS 2 & $(5) \pm 2.74 \pm 0.81$ & (5) $3.72 \pm 1.08$ \\
FS 3 & $(5) 3.31 \pm 0.95$ & (3) $4.09 \pm 0.84$ \\
FS 5 & (8) $2.78 \pm 0.41$ & (8) $3.19 \pm 0.84$ \\
Control mean & (2) $2.13 \pm 0.45$ & (2) $3.64 \pm 0.88$ \\
& (4) $2.73 \pm 0.48$ & (4) $3.66 \pm 0.37$
\end{tabular}

Patients

MSUD
GM612 (classical)
$\mathrm{CH}$ (intermittent)
(2) $0.08 \pm 0.02$
(5) $0.07 \pm 0.02$
SR (intermittent)
(4) $0.09 \pm 0.03$
(3) $0.04 \pm 0.02$
$\mathrm{KF}$ (intermittent)
TK ( $E_{3}$ deficiency)
(3) $0.07 \pm 0.02$
(5) $0.06 \pm 0.02$
(3) $0.79 \pm 0.20$
(2) $0.09 \pm 0.05$
(3) $0.09 \pm 0.03$
(2) $0.16 \pm 0.10$
(3) $0.92 \pm 0.40$
(1) 0.16

BCKADH, PDH, $\alpha \mathrm{KGDH} . \mathrm{E}_{3}$ normal)

* The values represent the mean \pm SD nmol per $2 \times 10^{6}$ cells per 90 min. Specific activity of $1-{ }^{14} \mathrm{C}$-leucine and $1-{ }^{14} \mathrm{C}$-valine was $0.4 \mathrm{mCi} /$ mmol.

† Additional abbreviations include: PDH, pyruvate dehydrogenase; $\alpha \mathrm{KGDH}, \alpha$-ketoglutarate dehydrogenase.

$\ddagger$ The numbers in parentheses represent the number of experiments.

branched-chain ketoaciduria, lactic acidemia and $\alpha$-ketoglutaric aciduria had a deficiency of oxidation of $1-{ }^{14} \mathrm{C}$-leucine and 1 ${ }^{14} \mathrm{C}$-valine to ${ }^{14} \mathrm{CO}_{2}$ that was similar to those of the patients with MSUD at 4 and $6 \%$ of the control mean.

Studies were carried out using uniformly labeled valine in order to determine the nature of the catabolic products of these amino acids in cultured human fibroblasts. The LPC profile of radioactive organic acid metabolites of UL- ${ }^{14} \mathrm{C}$-valine in normal fibroblasts is shown in Figure $4 A$, along with the blank without fibroblasts (dotted line). The largest radioactive peak eluted at the position of $\beta$-hydroxyisobutyric acid. This is a metabolite in the catabolic pathway of valine, but it was unexpected that it was the major metabolic product. The peak was substantially larger than that of $\alpha$-ketoisovaleric acid, the second largest peak. The pattern of the blank incubated without fibroblasts revealed a considerable amount of contaminating isotopic material. The largest peak eluted at the position of acetic acid. This was greatly decreased in incubations with normal fibroblasts, suggesting that it was metabolized. In fibroblasts of the patient with intermittent BCKADH deficiency (Fig. $4 B$ ) there was a large amount of isotope in the peak of $\alpha$-ketoisovaleric acid but almost none in $\beta$-hydroxyisobutyric acid.

Patients with classical or intermittent MSUD converted less than $1 \%$ as much valine to $\beta$-hydroxybutyric acid as did the control (Table 2). This is consistent with the finding of 1 to $3 \%$ of normal activity of BCKADH observed in the oxidation of 1 ${ }^{14} \mathrm{C}$-valine to ${ }^{14} \mathrm{CO}_{2}$ (Table 1). In the cells of the patient with deficiency of $E_{3} 7 \%$ of the control level of isotope was found in ${ }^{14} \mathrm{C}-\beta$-hydroxyisobutyric acid (Table 2 ) and this is consistent with the greater activity of BCKADH found in the oxidation of 1 ${ }^{14} \mathrm{C}$-valine to ${ }^{14} \mathrm{CO}_{2}$ (Table 1). The patient with BCKADH deficiency, lactic acidemia, and $\alpha$-ketoglutaric aciduria produced $2.5 \%$ of the ${ }^{14} \mathrm{C}-\beta$-hydroxyisobutyric acid from valine as did the control cells (Table 2). Control fibroblasts incubated with UL-

${ }^{14} \mathrm{C}$-leucine produced large amounts of $\alpha$-ketoisocaproic acid and a peak eluting at the position of $\beta$-hydroxyisovaleric acid as the second most abundant metabolite (Table 2 ). $\beta$-Hydroxyisovaleric acid is presumably formed by the hydration of $\beta$-methylcrotonyl$\mathrm{CoA}$. The production of ${ }^{14} \mathrm{C}-\beta$-hydroxyisovaleric acid from UL${ }^{14} \mathrm{C}$-leucine was greatly reduced in fibroblasts of all of the patients
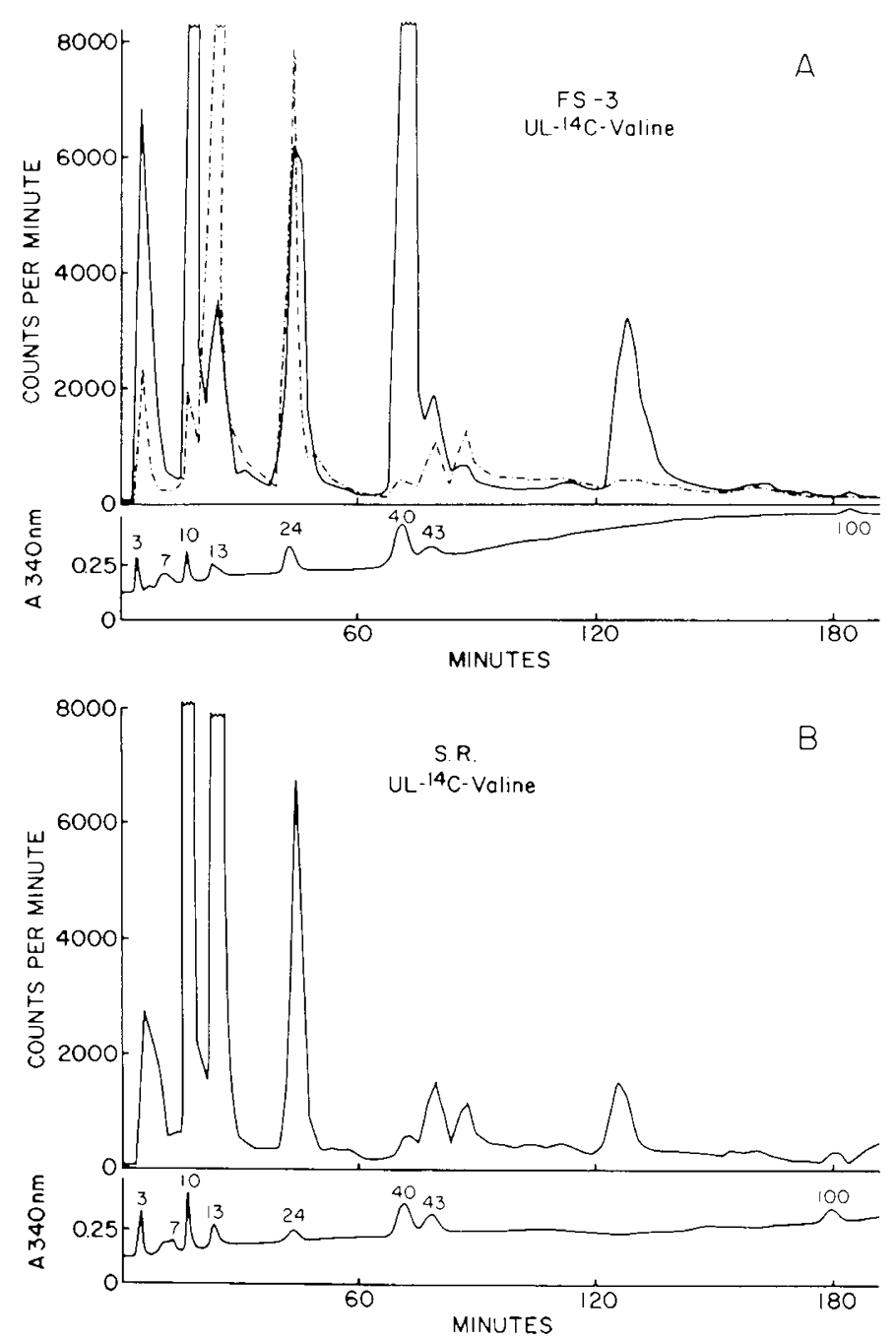

Fig. 4. Conversion of uniformly labeled ${ }^{14} \mathrm{C}$-valine to organic acid metabolites in cultured fibroblasts of a control individual (FS-3) $(A)$ and a patient with the intermittent MSUD phenotypes (SR) (B). The upper portion represents the radioactive products and the lower line the titratable added standard and endogenous organic acids. The numbered peaks were 3 , isobutyric and methylacrylic acids; 7, propionic acid; $10, \alpha$-KIVA oxime and $\alpha$-HIVA, 13 , acetic acid; 24 , formic acid; $40, \beta$-hydroxyisobutyric acid: 43 , lactic acid: and 100 . citric acid. The dotted line above in the control represents the blank without fibroblasts; $2 \times 10^{6}$ fibroblasts were incubated $90 \mathrm{~min}$ with $1 \mathrm{mmol} / \mathrm{liter}(4 \mathrm{mCi} / \mathrm{mmol})$ of $U \mathrm{~L}^{14}{ }^{14} \mathrm{C}$ valine and products analyzed by liquid partition chromatography as described in "Materials and Methods."

and paralleled the blank in the formation of ${ }^{14} \mathrm{C}-\beta$-hydroxyisobutyric acid from UL- ${ }^{14} \mathrm{C}$-valine (Table 2).

\section{DISCUSSION}

The metabolism of the branched-chain amino acids leucine and valine in normal cultured fibroblasts displayed certain similarities and some major differences. Oxidation of each substrate to $\mathrm{CO}_{2}$ was quite similar, as studied over $120 \mathrm{~min}$ using $1-{ }^{14} \mathrm{C}$ labeled leucine and valine. There was a close parallel between the conversion of leucine- $1-{ }^{14} \mathrm{C}$ to ${ }^{14} \mathrm{CO}_{2}$ and its conversion to $\alpha$ ketoisocaproic acid and its hydroxy acid. However, in the case of valine- $1-{ }^{14} \mathrm{C}$ there was considerably more isotope in ${ }^{14} \mathrm{CO}_{2}$ than in the corresponding $\alpha$-ketoisovaleric and $\alpha$-hydroxy acids. The major metabolic product of valine was $\beta$-hydroxyisobutyric acid. The amounts of isotope in this compound were somewhat 
METABOLISM OF BRANCHED-CHAIN AMINO ACIDS

Table 2. Conversion of ${ }^{14} \mathrm{C}$-valine and ${ }^{14} \mathrm{C}$-leucine to organic acid metabolites ${ }^{*} \dagger$

\begin{tabular}{|c|c|c|c|c|c|c|}
\hline \multirow[b]{2}{*}{ Cell line } & \multicolumn{2}{|c|}{ Substrate:- $1-{ }^{14} \mathrm{C}$-leucine } & \multirow{2}{*}{$\frac{\text { UL- }^{-14} \mathrm{C} \text {-leucine }}{\beta \text {-HIVA }}$} & \multicolumn{2}{|c|}{$1-{ }^{14} \mathrm{C}$-valine } & \multirow{2}{*}{$\frac{\mathrm{UL}^{14} \mathrm{C} \text {-valine }}{\beta \text {-HIBA }}$} \\
\hline & Product:- $-\alpha-\mathrm{KICA}$ & $\alpha$-HICA & & $\alpha$-KIVA & $\alpha$-HIVA & \\
\hline \multicolumn{7}{|l|}{ Control } \\
\hline FS-3 & 11.36 & 0.05 & 1.70 & 3.53 & 0.34 & 4.91 \\
\hline FS-5 & 5.98 & 0.01 & & 2.09 & 0.16 & \\
\hline \multicolumn{7}{|l|}{ Patient } \\
\hline \multicolumn{7}{|l|}{ MSUD } \\
\hline GM612 (classical) & 7.39 & 0.06 & 0.00 & 2.46 & 0.31 & 0.00 \\
\hline SR (intermittent) & & & 0.01 & & & 0.01 \\
\hline KF (intermittent) & 8.41 & 0.13 & 0.01 & 1.57 & 0.59 & 0.00 \\
\hline TK $\left(E_{3}\right.$ deficiency $)$ & & & 0.07 & & & 0.38 \\
\hline $\begin{array}{l}\text { EB (deficiency BCKADH, } \\
\text { PDH, } \alpha \mathrm{KGDH}, \mathrm{E}_{3} \text { normal) }\end{array}$ & & & 0.08 & & & 0.12 \\
\hline
\end{tabular}

* The values represent the nmol per $2 \times 10^{6}$ cells per $90 \mathrm{~min}$. Specific activity $=0.4 \mathrm{mCi} / \mathrm{mmol}$ for $\alpha$-KIVA, $\alpha$-HIVA, $\alpha$-KICA and $\alpha$-HICA; specific activity $=(4 / 5) \times 4.0 \mathrm{mCi} / \mathrm{mmol}$ for $\beta$-HIBA and $(5 / 6) \times 4.0 \mathrm{mCi} / \mathrm{mmol}$ for $\beta$-HIVA.

+ Additional abbreviations include: $\alpha$-KIVA, $\alpha$-ketoisovaleric acid; $\alpha$-HIVA, $\alpha$-hydroxyisovaleric acid; $\beta$-HIBA, $\beta$-hydroxyisobutyric acid; $\alpha$ KICA, $\alpha$-ketoisocaproic acid; $\alpha$-HICA, $\alpha$-hydroxyisocaproic acid; $\beta$-HIVA, $\beta$-hydroxyisovaleric acid.

higher than that in the sum of $\alpha$-ketoisovaleric and $\alpha$-hydroxyisovaleric acids. In the metabolism of leucine, a major metabolic product was $\beta$-hydroxyisovaleric acid. In this case the amounts of isotope in this compound were about one-tenth as great as that in $\alpha$-ketoisocaproic acid.

These observations indicate that leucine is normally rapidly converted in fibroblasts to $\beta$-methylcrotonyl $\mathrm{CoA}$ and that this compound is promptly hydrated to form $\beta$-hydroxyisovaleric acid. In normal fibroblasts valine is even more rapidly catabolized beyond the initial $\alpha$-keto acid step. Accumulation is at the level of $\beta$-hydroxyisobutyric acid. The accumulation in each instance of the $\beta$-hydroxy acid is of interest. It could reflect a more reducing environment in the fibroblast, possibly the ratio of NADH to NAD.

The data obtained are consistent with studies of the conversion of the ketoacid analogs of the branched-chain amino acids to $\mathrm{CO}_{2}$ in which $\alpha$-ketoisovalerate is catabolized more rapidly than $\alpha$-ketoisocaproic acid. Purified branched-chain $\alpha$-ketoacid dehydrogenase displays a higher rate of conversion of $\alpha$-ketoisovalerate to ${ }^{14} \mathrm{CO}_{2}$ than that of $\alpha$-ketoisocaproate; study of the reduction of NAD revealed the same pattern; and there was a 1:1:1 stoichiometry of ${ }^{14} \mathrm{CO}_{2}$ formation, NAD reduction and acyl CoA formation $(10,11)$. On the other hand, the apparent $\mathrm{V}_{\max }$ values for $\alpha$-ketoisocaproic acid and $\alpha$-ketoisovaleric acid as substrates for the purified dehydrogenase were very similar (12), and this is consistent with the fact that our rates of conversion of labeled leucine and valine to ${ }^{14} \mathrm{CO}_{2}$ were quite similar. Apparent $K_{m}$ values for the three ketoacids were very similar (11). In normal fibroblasts in culture, activity of branched-chain ketoacid dehydrogenase is increased by cultivation in high concentration of branched-chain amino acids, a form of regulation that is absent in intact cells with deficient dehydrogenase activity (13). $\mathrm{BCKADH}$ is a rate-limiting step in the catabolism of branchedchain amino acids and this is thought to play an important role in determining the concentrations of branched-chain amino acids in blood and tissues. The dehydrogenase appears to be regulated by covalent modification in a phosphorylation-dephosphorylation mechanism analogous to that of pyruvate dehydrogenase (14). $\alpha$-Ketoisocaproic acid, and to a considerably lesser extent the other branched-chain ketoacids, regulate the activity of the dehydrogenase by inhibiting the kinase that catalyzes its phosphorylation, which would account for the unique properties of leucine in regulating the activity of branched-chain ketoacid dehydrogenase.

Accumulations of $\beta$-hydroxyisovaleric acid and $\beta$-hydroxyisobutyric acid have been described as concomitants of ketosis, even in normal individuals (15). These compounds have been recognized as products of leucine and valine (15). $\beta$-Hydroxy- $\beta$-methylglutaryl CoA, the key intermediate in ketogenesis, has been thought not to be an intermediate in the formation of these compounds. The complete absence of conversion of the branched-chain amino acids to these hydroxy acids in cells of the patient with classic MSUD indicates that the formation of these compounds requires metabolism beyond the initial $\alpha$-keto acid step, presumably to $\beta$-methylcrotonyl $\mathrm{CoA}$ and $\beta$-hydroxyisobutyryl CoA. There is a pathway in liver in which $\beta$-hydroxyisovaleric acid may be formed from $\alpha$-ketoisocaproic acid in a reaction catalyzed by $\alpha$-ketoisocaproate oxidase $(16,17)$. Our data indicate that this pathway is not normally present in cultured human fibroblasts, since there was no conversion to this product in cells of the patient with MSUD. Thus in normal fibroblasts all of the $\beta$-hydroxyisovaleric acid formed must come via the usual pathway which is blocked in MSUD.

The patients with defects in metabolism all had defective conversion of leucine and valine to ${ }^{14} \mathrm{CO}_{2}$. Furthermore, the patients with associated defective metabolism of pyruvate and $\alpha$ ketoglutarate had much less complete deficiency in these oxidative decarboxylations. However, among the patients with branched-chain ketoaciduria and clinical manifestations of MSUD the conversion of leucine- $1-{ }^{14} \mathrm{C}$ was virtually identical in the patient with classic MSUD and two patients with an intermittent clinical phenotype. The amount of isotope of valine-1. ${ }^{14} \mathrm{C}$ in ${ }^{14} \mathrm{CO}_{2}$ in these two patients was more than twice that of the patient with classic MSUD, but these values represented only 2.7 versus $1 \%$ of the control mean. These data do not seem to indicate that valine is any better tracer than leucine in distin. guishing among different variants of the BCKADH. Although there was somewhat higher residual activity in the patients with intermittent branched ketoaciduria when valine was the sub. strate, the SDs were sufficiently great that these differences do not appear to be significant.

The oxidation of leucine to $\mathrm{CO}_{2}$ has generally been employed in the assay of BCKADH, and it is reliable in the demonstration of low rates of production of $\mathrm{CO}_{2}$ from leucine in fibroblasts of patients with MSUD; while $\alpha$-ketoisocaproic acid may not be a reliable substrate for this purpose because normal rates of decarboxylation may be seen when substrate concentrations are high $(18,19)$. In the presence of high extracellular concentrations of the keto acid its intracellular concentrations become very high and there is a low affinity decarboxylating system, present in patients with MSUD as well as normals, which acts on $\alpha$ ketoisocaproic acid at high concentrations $(6,18,20-23)$. When 
leucine is the substrate intracellular concentrations remain low (20); thus the amino acid is a better substrate than the keto acid for demonstration of the defect in patients with MSUD. Furthermore, blanks are lower when the amino acid is used.

Assessment of the conversion of labeled leucine or valine to their major metabolic products distal to the block provides alternative approaches to the assay of BCKADH activity in various patients. In classic MSUD we found the conversion of valine to $\beta$-hydroxyisobutyrate and of leucine to $\beta$-hydroxyisovalerate to be zero. In patients with secondary defects in which there was also defective metabolism of pyruvate and $\alpha$-ketoglutarate there were appreciable amounts of isotope in these products and at the same time clear evidence of deficiency. The conversion of leucine to $\beta$-hydroxyisovaleric acid in the two patients was $4.5 \%$ of control. Similarly in the patient in whom $\mathrm{E}_{3}$ was normal the conversion of valine to $\beta$-hydroxyisovaleric acid was $2.5 \%$ of control. In the patient with $\mathrm{E}_{3}$ deficiency the value was $7.7 \%$ of control. In both of the variants with the intermittent phenotype there was isotope in $\beta$-hydroxyisovalerate after incubation with leucine. After incubation with valine there was evidence of isotope in $\beta$-hydroxyisobutyric acid in only one of the two patients, but the amount was more than following leucine. These observations suggest that simple demonstration of defective oxidation of leucine to $\mathrm{CO}_{2}$ should be sufficient for the characterization of a patient with classic MSUD. On the other hand, the careful study of patients with variant forms may be elucidated by a metabolic study in which the major metabolic products are determined. In this study this proved not to be the case for those patients with the intermittent phenotype. Of those with the associated deficiency of metabolism of $\alpha$-ketoglutarate and pyruvate, distinction from classic MSUD could readily be made by the study of $\mathrm{CO}_{2}$ or the metabolic products. The distinction of EB from those with the intermittent phenotype was better using the LPC method. That these kinds of data may have clinical relevance is suggested by the report of a patient with intermittent MSUD who appeared to be valine toxic (24).

In the leucine metabolism of fibroblasts as well as other nonhepatic tissues, the dehydrogenase reaction of the branchedchain ketoacid is thought to be limiting $(20,25-27)$. This is consistent with the fact that the concentrations of $\alpha$-ketoisocaproic acid in fibroblasts of patients with MSUD are not much lower than those of control fibroblasts (20). It is also consistent that in our studies the amounts of isotope in $\beta$-hydroxyisovaleric acid were considerable, but smaller than that in $\alpha$-ketoisocaproic acid following the incubation of control fibroblasts with leucine. On the other hand, the observations that there are substantial accumulations of $\beta$-hydroxyisovaleric acid in normal fibroblasts suggest that the carboxylation of $\beta$-methylcrotonyl CoA may also be limiting and that this compound is then hydrated to form $\beta$ hydroxyisovaleric acid. In the metabolism of valine the amounts of isotope in $\beta$-hydroxyisobutyric acid were considerably greater than in $\alpha$-ketoisovaleric acid, suggesting that in the case of this amino acid the BCKADH step is not the limiting one.

\section{REFERENCES}

1. Dancis J, Hutzler J, Levitz M 1963 The diagnosis of maple syrup urine disease (branched-chain ketoaciduria) by the in vitro study of the peripheral leukocyte. Pediatrics 32:234-238

2. Sakaguchi Y, Okada S, Yoshino M, Yasuoka C, Yoshida I, Watari H, Koga Y, Aramaki S. Yamashita F 1983 A case report of maple syrup urine disease with normal psychomotor development. Acta Paediatr Jap 87:2426-2435
3. Dancis J, Hutzler J, Rokkones T 1983 Intermittent branched-chain ketonuria: variant of maple syrup urine disease. N Engl J Med 276:84-89

4. Dancis J, Hutzler J, Snyderman SE, Cox RP 1972 Enzyme activity in classical and variant forms of maple syrup urine disease. J Pediatr 81:312-320

5. Kuhara T, Shinka T, Inoue Y, Matsumoto M, Yoshino M, Sakaguchi Y, Matsumoto I 1983 Studies of urinary organic acid profiles of a patient with dihydrolipoyl dehydrogenase deficiency. Clin Chim Acta 133:133-141

6. Robinson BH, Taylor J, Sherwood WG 1977 Deficiency of dihydrolipoyl dehydrogenase (a component of the pyruvate and $\alpha$-ketoglutarate dehydrogenase complexes): a cause of congenital chronic lactic acidosis in infancy. Pediatr Res 11:1198-1202

7. DeLuca HF, Cohen PP 1964 Suspending media for animal tissues. In: Umbreit WW, Burris RH, Stauffer JF (eds) Manometric Techniques, 4th ed. Burgess, Minneapolis, pp 131-133

8. Husain S, Paradise RR 1973 Pitfalls in measurement of ${ }^{14} \mathrm{CO}_{2}$ activity from glucose- $6-{ }^{14} \mathrm{C}$ and two correction procedures. Proc Soc Exp Biol Med $142: 316-320$

9. Sweetman L 1984 Qualitative and quantitative analysis of organic acids in physiologic fluids for diagnosis of the organic acidurias. In: Nyhan WL (ed) Abnormalities in Amino Acid Metabolism in Clinical Medicine. AppletonCentury-Crofts, Norwalk, CT, pp 419-453

10. Danner DJ, Lemmon SK, Besharse JC, Elsas LJ 1979 Purification and characterization of branched chain $\alpha$-ketoacid dehydrogenase from bovine liver mitochondria. J Biol Chem 254:5522-5526

11. Pettit FH, Yeaman SJ, Reed LJ 1978 Purification and characterization of branched chain $\alpha$-keto acid dehydrogenase complex of bovine kidney. Proc Natl Acad Sci 75:4881-4885

12. Randle PJ, Lau KS, Parker PJ 1981 Regulation of branched-chain 2-oxoacid dehydrogenase complex. In: Walter M, Williamson JR (eds) Metabolism and Clinical Implications of Branched Chain Amino and Ketoacids, Vol 18, Elsevier/North-Holland, Inc, New York, pp 13-22

13. Danner DJ, Priest JH 1983 Branched-chain ketoacid dehydrogenase activity and growth of normal and mutant human fibroblasts: the effect of branchedchain amino acid concentration in culture medium. Biochem Genet 21:895905

14. Harris RA, Paxton R 1985 Regulation of branched chain $\alpha$-ketoacid dehydrogenase complex by phosphorylation-dephosphorylation. Fed Proc 44:305 315

15. Landaas S 1975 Accumulation of 3-hydroxybutyric acid, 2-methyl-3-hydroxybutyric acid and 3-hydroxyisovaleric acid in lactic acidosis. Clin Chim Acta 64:143-154

16. Sabourin PJ, Bieber LL 1981 Subcellular distribution and partial characterization of $\alpha$-ketoisocaproate oxidase of rat liver: formation of $\beta$-hydroxyisovaleric acid. Arch Biochem Biophys 206:132-144

17. Sabourin PJ, Bieber LL 1983 Formation of beta-hydroxyisovalerate by alphaketoisocaproate oxygenase in human liver. Metabolism 32:160-164

18. Wendel U, Wentrup H, Rüdiger HW 1975 Maple syrup urine disease: Analysis of branched chain ketoacid decarboxylation in cultured fibroblasts. Pediatr Res 9:709-717

19. Dancis J, Hutzler J, Cox RP 1977 Maple syrup urine disease: branched-chain keto acid decarboxylation in fibroblasts as measured with amino acids and keto acids. Am J Hum Genet 29:272-279

20. Wendel U, Langenbeck U 1984 Intracellular levels and metabolism of leucine and $\alpha$-ketoisocaproate in normal and maple syrup urine disease fibroblasts. Biochem Med 31:294-302

21. Chuang DT, Niu W-L, Cox RP 1981 Activities of branched-chain 2-oxo acid dehydrogenase and its components in skin fibroblasts from normal and classical maple-syrup-urine-disease subjects. Biochem J 200:59-67

22. Rüdiger HW, Langenbeck U, Schultze-Schencking M, Goedde HW 1972 Defective decarboxylase in branched chain ketoacid oxidase multienzyme complex in classic type of maple syrup urine disease. Humangenetik 14:257263

23. Snyderman SE, Goldstein F, Sansaricq C, Norton PM 1984 The relationship between the branched chain amino acids and their alpha-ketoacids in MSUD. Pediatr Res 18:851-853

24. Zipf WB, Hieber VC, Allen RJ 1979 Valine-toxic intermittent maple syrup urine disease: a previously unrecognized variant. Pediatrics 63:286-294

25. Hutson SM, Zapalowski C, Cree TC, Harper AE 1980 Regulation of leucine and $\alpha$-ketoisocaproic acid metabolism in skeletal muscle. $\mathrm{J}$ Biol Chem $255: 2418-2426$

26. Shinnik FL, Harper AE 1976 Branched-chain amino acid oxidation by isolated rat tissue preparations. Biochim Biophys Acta 437:477-486

27. Khatra BS, Chawla RK, Sewell CW, Rudman D 1977 Distribution of branchedchain $\alpha$-keto acid dehydrogenases in primate tissues. $J$ Clin Invest 59.558564 